\title{
Hormonal contraception in patients with epilepsy
}

\author{
Magdalena Bosak, Katarzyna Cyranka, Agnieszka Slowik \\ Collegium Medicum, Jagiellonian University of Cracow, Poland
}

\begin{abstract}
Objectives: The aim of the study was to evaluate hormonal contraception use in women with epilepsy and to assess the risk of potential interactions between contraceptives and antiepileptic drugs (AEDs).

Material and methods: Data on hormonal contraception were obtained prospectively in women of childbearing age treated in the university epilepsy clinic.

Results: We evaluated 334 women with epilepsy (mean age 30.2 years). The majority of patients took one AED (193, 58\%); the most commonly prescribed AEDs were: valproate, levetiracetam or lamotrigine. Hormonal contraception was used by $19(5.7 \%)$ of all women of childbearing age. Only 7 patients (37\%) of all those using hormonal contraception used preparations that did not interact with AEDs; what is more $145(46 \%)$ patients who did not use hormonal contraception were prescribed AEDs with high teratogenic potential (valproate or/and topiramate).

Conclusions: A very small percentage of women with epilepsy of childbearing potential used hormonal contraception. More than a half of that group simultaneously took AEDs that may interact with oral contraceptives. A large proportion of women taking AEDs with high teratogenic potential were not using hormonal contraception. As interaction between OC and AEDs are common, nonhormonal, highly effective methods, such as IUDs, may be ideal for women with epilepsy. The results of the study indicate the need for closer cooperation between neurologist and gynecologist caring for women with epilepsy. Key words: hormonal contraception; epilepsy; antiepileptic drugs; interaction
\end{abstract}

Ginekologia Polska 2019; 90, 2: 61-65

\section{INTRODUCTION}

With an estimated point prevalence of 6.4 per 1,000 persons, epilepsy is one of the most frequent chronic neurological disorders [1]. Both epileptic seizures and their pharmacotherapy may negatively affect reproductive health-related issues, especially in women with epilepsy (WWE). Antiepileptic drugs (AEDs) must be used in WWE for many years, and sometimes throughout life, also during reproductive age. One of the most important side effects of pharmacotherapy of WWE is the teratogenic potential of AEDs. The results of prospective observational registers of pregnancies in WWE indicate an increased risk of birth defects in children exposed to AEDs in utero. The latest report of the largest pregnancy and epilepsy register EURAP International showed $4.9 \%$ risk of major congenital malformation in offspring of women taking AEDs during pregnancy [2]. Another aspect of the treatment of epilepsy in women are the bidirectional pharmacokinetic interactions between oral contraceptives (OC) and AEDs, which may lead to a reduction in the effectiveness of contraception and/or AEDs [3]. Ethinylestradiol (EE) metabolism may be accelerated by carbamazepine, oxcarbazepine, phenytoin, phenobarbital and high doses of topiramate (> $200 \mathrm{mg} / \mathrm{d}$ ), progestin by carbamazepine, oxcarbazepine, lamotrigine, phenytoin and phenobarbital. Other AEDs interacting with $\mathrm{OC}$ are not available in Poland. Lamotrigine concentration is reduced by $E E$ and increased seizure frequency has been reported. Interaction of EE with AEDs are well known, however possible interactions of progestin with AEDs are much less studied. It has been proved that enzyme-inducing AEDs interact with oral levonorgestrel, oral norethindrone and the subdermal etonogestrel implant [3]. According to recent data more than half of pregnancies in women with epilepsy are unplanned; significant percentage of patients do not use highly effective methods of contraception or use hormonal contraceptives combined with enzyme-inducing AEDs, which can lead to unintended pregnancies [4-6]. 


\section{Objectives}

The aim of the study was to evaluate hormonal contraception use in women with epilepsy and to assess the risk of potential interactions between contraceptives and antiepileptic drugs.

\section{MATERIAL AND METHODS}

\section{Study population}

The study included consecutive WWE of reproductive age (16-49 years) treated at the university epilepsy clinic between 01.08. 2017 and 31.08.2018. Participation in the study was offered to patients diagnosed with epilepsy as defined by the International League Against Epilepsy (ILAE) of 2014 [7]. Patients who did not agreed to participate, pregnant and breastfeeding patients, patients with primary amenorrhea and patients with concomitant psychogenic non-epileptic seizures were excluded from the study.

The study protocol was approved by the University Ethical Committee and all subjects gave their written consent to participate in the study.

\section{Methods}

Demographic and epilepsy data were collected using a structured questionnaire and included: age, sex, age at the onset of epilepsy, type and frequency of seizures, AEDs treatment. The type of epilepsy was diagnosed on the basis of the interview, neurological examination, neuroimaging and electroencephalogram. Epilepsy type has been classified according to the new ILAE position paper on classification of epilepsies [8]. Data on hormonal contraception used by patients were obtained prospectively from patients during two subsequent visits to the clinic. The potential for interaction between AEDs and hormonal contraceptives has been assessed on the basis of Reimers et al. [3]. Enzyme-inducing AEDs used by studied women included carbamazepine, oxcarbazepine and topiramate $>200 \mathrm{mg}$ daily.

\section{RESULTS}

\section{Sample characteristics}

Among 405 female patients who were seen in the epilepsy clinic within the period of the study, 334 fertile women met the inclusion criteria and entered the study. The average age of the analyzed patients was 30.2 ( \pm 7.73 ). 193 (57.8\%) patients were on monotherapy, polytherapy was used in 141 (42.2\%) of the studied women. The most commonly used AEDs included valproate, levetiracetam and lamotrigine. At the time of the assessment 127 (36.2\%) of the patients were in remission. Counseling regarding the effective methods of contraception and the possible teratogenic effects of the medication on the fetus were documented in a written form in patients' health records in all WWE taking
Table 1. Clinical characteristics of the study patients

\begin{tabular}{|c|c|}
\hline Variable & $\mathbf{N}=334$ \\
\hline $\begin{array}{l}\text { Age [years] } \\
\text { Age at onset of epilepsy }\end{array}$ & $\begin{array}{l}30.2(16-49) \\
15.0(1-43)\end{array}$ \\
\hline $\begin{array}{l}\text { Type of epilepsy } \\
\text { - focal } \\
\text { - genetic (idiopathic) generalized } \\
\text { - combined focal \& generalized or unknown }\end{array}$ & $\begin{array}{l}227(70.0 \%) \\
96(28.7 \%) \\
11(3.3 \%)\end{array}$ \\
\hline $\begin{array}{l}\text { Number of AEDs used } \\
\text { - } 1 \\
\text { - } 2 \\
\text { - } 3 \\
\text { - } 4\end{array}$ & $\begin{array}{l}193(57.8 \%) \\
104(31.2 \%) \\
32(9.6 \%) \\
5(1.4 \%)\end{array}$ \\
\hline $\begin{array}{l}\text { Seizure frequency } \\
\text { - more than } 1 \text { per month } \\
\text { - less than } 1 \text { per month, more than } 1 \text { per year } \\
\text { - less than } 1 \text { per year }\end{array}$ & $\begin{array}{l}121(36.2 \%) \\
86(25.8 \%) \\
127(38.0 \%)\end{array}$ \\
\hline \multicolumn{2}{|c|}{ The most commonly used AEDs (in mono-or polytherapy) } \\
\hline $\begin{array}{l}\text { Valproate } \\
\text { - levetiracetam } \\
\text { - lamotrigine } \\
\text { - carbamazepine } \\
\text { - topiramate }\end{array}$ & $\begin{array}{l}135 \\
121 \\
98 \\
56 \\
39\end{array}$ \\
\hline $\begin{array}{l}\text { Place of residence } \\
\text { - } \quad \text { village or town }<20000 \\
\text { - large town } 20000-100000 \\
\text { - city } 100000-1000000\end{array}$ & $\begin{array}{l}198(59.3 \%) \\
80(24 \%) \\
56(16.7 \%)\end{array}$ \\
\hline $\begin{array}{l}\text { Education } \\
\text { - none } \\
\text { - } \text { primary school } \\
\text { - vocational/secondary school } \\
\text { - university degree }\end{array}$ & $\begin{array}{l}68(20.3 \%) \\
18(5.4 \%) \\
201(60.2 \%) \\
47(14.1 \%)\end{array}$ \\
\hline
\end{tabular}

valproate or/and topiramate and in $89 \%$ (297) of the whole group. Table 1 presents demographics, the characteristics of epilepsy and its treatment in the studied group.

\section{Hormonal contraception}

Of the 334 WWE participating in the study, 19 (5.7\%) patients in an average age of $27.6(20-43)$ years reported the current use of hormonal contraception (18-combined hormonal contraceptive, 1 progestin-only pill). No women used hormonal patch, vaginal ring, implanted progestin or depomedroxyprogesterone. The precise characteristics of AEDs used by these patients as well as hormonal contraception are presented in Table 2.

Of the patients on OC, the majority $(12 ; 63 \%)$ had a potential for drug-drug interactions. Only 7 women (37\%) of all those on hormonal contraception used preparations that did not interact with AEDs. Additionally 7 patients used sex hormones for other indications (menstrual regulation or hormone replacement therapy): 2 patients — dydrogesterone, 2 - progesterone, 1 - estradiol, 1 - estradiol / norethisterone, 1 - estradiol / norgestrel. All patients from this group were on non-enzyme-inducing AEDs (LEV, VPA, VGB). 
Table 2. Hormonal contraceptives, AEDs and interaction risk in the studied patients

\begin{tabular}{|c|c|c|c|}
\hline AEDs & Estrogen & Progestogen & Interaction risk ${ }^{a}$ \\
\hline OXC & estradiol & nomegestrol & 1 \\
\hline CBZ & ethinylestradiol & norgestimate & 1 \\
\hline LTG & ethinylestradiol & gestodene & 2 \\
\hline LEV & ethinylestradiol & gestodene & 3 \\
\hline LEV OXC & ethinylestradiol & gestodene & 1 \\
\hline OXC & ethinylestradiol & gestodene & 1 \\
\hline LEV & ethinylestradiol & norgestimate & 3 \\
\hline VPA & ethinylestradiol & norgestimate & 3 \\
\hline LEV LTG & ethinylestradiol & drospirenone & 2 \\
\hline VPA LTG LEV & ethinylestradiol & norgestimate & 2 \\
\hline VPA LEV & ethinylestradiol & norgestimate & 3 \\
\hline VPA & ethinylestradiol & norgestimate & 3 \\
\hline VPA LTG & ethinylestradiol & gestodene & 2 \\
\hline LTG & ethinylestradiol & dienogest & 2 \\
\hline VPA & ethinylestradiol & gestodene & 3 \\
\hline LTG & ethinylestradiol & norgestimate & 2 \\
\hline LTG & ethinylestradiol & gestodene & 2 \\
\hline LTG VGB & ethinylestradiol & dienogest & 2 \\
\hline LEV & & desogestrel & 3 \\
\hline
\end{tabular}

a 1 - reduced efficacy of OC; 2 - decreased concentration of AED; 3 - without clinically significant interactions; abbreviations: CBZ — carbamazepine; LTG — lamotrigine; LEV - levetiracetam; OXC — oxcarbazepine; VPA — valproate; VGB — vigabatrin

\section{AEDs with teratogenic potential}

Nearly half of the patients $(145 ; 46 \%)$ who did not use hormonal contraceptives were on AEDs with known teratogenic potential (128VPA, 17TPM). In 68 patients of the initial cohort the future pregnancy was extremely unlikely due to concurrent severe disabilities (severe mental retardation, being in a nursing home, significant paresis). They were excluded from the analysis. The remaining group consisted of 266 women, of whom 19 (7.1\%) used OC. Out of 247 WWE not using hormonal contraception, 84 (37\%) were on AEDs with the highest risk of teratogenicity: VPA or TPM.

\section{DISCUSSION}

Our work showed a very low percentage of WWE using hormonal contraceptives (5.7\%). In a study of patients with epilepsy in the US, as many as $46.6 \%$ used hormonal contraception [5]. The results of study by Polish authors, focused on general population also showed a significantly higher percentage of OC usage in the Polish general population (31.2\%) [9]. There may be several reasons for such a low percentage of $\mathrm{OC}$ usage in our cohort. With regard to religion, the vast majority of Polish population (88\%) is Roman catholic and may accept only methods of natural family planning [10]. Only $14 \%$ of patients had a university degree and most of them (60\%) lived in villages or small towns, these factor my negatively affect knowledge and availability of the effective contraceptive methods. Several other reasons may play a role in not using contraception by WWE: concerns about its efficacy and interactions with AEDs, sides effects of hormonal OC, menstrual problems and increased seizure frequency [11].

Every woman of childbearing age treated in our epilepsy clinic receives counseling on a contraception plan and on the teratogenicity of AEDs. Despite this, the proportion of patients using hormonal contraceptives is very low. In the case of using drugs with high risk of teratogenicity (VPA, TMP), the patient is counselled on effective methods of contraception during each subsequent visit, and a plan for changing the pharmacotherapy of epilepsy is also presented. Unfortunately, most patients, especially those who are in remission, do not agree to change therapy.

Furthermore, $60 \%$ of the patients taking oral contraceptives were on AEDs which could have significant pharmacokinetic interactions with hormonal preparations. These were: induction of hepatic metabolism of OC by CBZ or $\mathrm{OXC}$, and thus the possibility of reducing the contraceptive effectiveness. The second, more frequent mechanism of interaction, involved the stimulation of UDP-glucuronyl 
transferase by the estrogen component of hormonal contraception, thereby reduction of the concentration and efficacy of lamotrigine. Our results are in line with the study of Bhakta et al. [4] and indicate that knowledge gaps exist in terms of the potential teratogenic effects of AEDs and pharmacokinetic interactions between AEDs and OC.

Out of 247 childbearing age women who could become pregnant and did not use hormonal contraception, 84 (37\%) were on AEDs with the highest risk of teratogenicity: VPA or TPM. According to the recently published European Medicine Agency recommendation valproate must not be used in women able to have children unless the terms of a special pregnancy prevention programs are followed [12].

Appropriate counseling on the forms of hormonal contraception, suited for WWE expectations and needs is crucial for the selection of an optimal birth control method [11, 13]. Polish Society of Epileptology and Polish Gynecological Society have developed guidelines regarding management and care of WWE of childbearing potential, which underline the importance of counseling regarding contraceptive or pregnancy planning and the choice of AEDs [14].

Combined $O C$ and progestin-only pill efficacy may be reduced by enzyme-inducing AEDs. Other hormonal contraceptive methods, such as medroxyprogesterone acetate depot injection, or implantable hormonal contraceptive may have some interaction with AEDs. Nonhormonal, highly effective methods, such as IUDs, may be ideal for women with epilepsy, since the contraceptive mechanism of IUDs is unaffected by changes in hepatic enzyme activity [14-16]. What's more, IUD poses a significantly lower risk for seizure increase in WWE than hormonal contraception [17]. In WWE using a hormonal-IUD, a levonorgestrel level seems to be unaffected by concomitant AEDs therapy [18]. The role of gynecologist in counseling on the forms of hormonal contraception is indispensable for appropriate management of WWE in childbearing age.

Our research has several disadvantages. First of all, it was carried out in a reference outpatient epilepsy clinic in which we treat patients with drug-resistant epilepsy often requiring polytherapy or using drugs with a higher potential for teratogenicity. For this reason, a group of patients may not be representative of the general population of women with epilepsy. The second disadvantage is the lack of a control group. Therefore, it can only be concluded indirectly that the frequency of OC usage in patients with epilepsy is lower than in the Polish population of women in reproductive age. Thirdly, information on the use of other methods of contraception, in particular highly effective methods, such as the intrauterine device (tubal ligation and vasectomy are legally prohibited in Poland), has not been collected. In the studies of Bakhta et al. [4] and Herzog et al. [5], IUD was used by $6.1 \%$ and $17 \%$ of WWE respectively.

\section{CONCLUSIONS}

A very small percentage of WWE in reproductive age used oral hormonal contraception. The ones using contraception frequently applied method that had significant drug-drug interaction which reduced the effectiveness of OC or AED(s). A large proportion of women who were having AEDs with high risk of teratogenicity prescribed were not using hormonal contraception. It is advisable to create gynecological-neurological teams, caring for WWE in reproductive age, and to take care about continuous education of patients regarding effective methods of family planning and about improvement of methods of informing patients about the teratogenicity of AEDs. Nonhormonal, highly effective methods, such as IUDs, may be ideal for women with epilepsy.

\section{Acknowledgements}

Magdalena Bosak: Project development, data collection, literature review, writing manuscript; Katarzyna Cyranka: literature review, writing manuscript; Agnieszka Słowik: literature review, writing manuscript, intellectual input.

\section{Conflict of interest}

M. Bosak received honoraria for publications from Sanofi; honoraria for lectures, travel expenses and conference fees from Sanofi, Adamed, Teva Pharmaceutical, Neuraxpharm, Glenmark, UCB Pharma.

K. Cyranka reports no conflict of interest.

A. Słowik received honoraria for lectures from Bayer, Boehringer Ingelheim, Novartis, Polpharma, Bristol-Myers Squipp, Novartis, Biogen, Teva Pharmaceutical, Medtronic; for the participation in advisory meetings from Bayer, Boehringer Ingelheim, Novartis.

\section{Funding}

This publication was prepared without any external sources of funding.

\section{REFERENCES}

1. Jette N, Fiest KM, Sauro KM, et al. Prevalence and incidence of epilepsy: A systematic review and meta-analysis of international studies. Neurology. 2017; 88(3): 296-303, doi: 10.1212/WNL.0000000000003509, indexed in Pubmed: 27986877.

2. EurapInternational http://eurapinternational. http://eurapinternational.org/wp-content/uploads/2018/09/Eurap_Report_May_2018. pdf (2018.09.15).

3. Reimers A, Brodtkorb E, Sabers A. Interactions between hormonal contraception and antiepileptic drugs: Clinical and mechanistic considerations. Seizure. 2015; 28:66-70, doi: 10.1016/j.seizure.2015.03.006, indexed in Pubmed: 25843765.

4. Bhakta J, Bainbridge J, Borgelt L. Teratogenic medications and concurrent contraceptive use in women of childbearing ability with epilepsy. Epilepsy Behav. 2015; 52(Pt A): 212-217, doi: 10.1016/j. yebeh.2015.08.004, indexed in Pubmed: 26460786.

5. Herzog AG, Mandle HB, Cahill KE, et al. Contraceptive practices of women with epilepsy: Findings of the epilepsy birth control registry. 
Epilepsia. 2016; 57(4): 630-637, doi: 10.1111/epi.13320, indexed in Pubmed: 26880331.

6. Herzog A, Mandle $\mathrm{H}$, Cahill $\mathrm{K}$, et al. Predictors of unintended pregnancy in women with epilepsy. Neurology. 2017; 88(8): 728-733, doi: 10.1212/wnl.0000000000003637.

7. Fisher RS, Acevedo C, Arzimanoglou A, et al. ILAE official report: a practical clinical definition of epilepsy. Epilepsia. 2014; 55(4): 475-482, doi: 10.1111/epi.12550, indexed in Pubmed: 24730690.

8. Scheffer IE, Berkovic S, Capovilla G, et al. ILAE classification of the epilepsies: Position paper of the ILAE Commission for Classification and Terminology. Epilepsia. 2017; 58(4): 512-521, doi: 10.1111/epi.13709, indexed in Pubmed: 28276062.

9. Plany prokreacyjne i stosowanie antykoncepcji przez Polaków w wieku reprodukcyjnym. Zdrowie Publiczne i Zarządzanie. 2017; 15(2), doi: 10.4467/20842627oz.17.013.6783.

10. http://stat.gov.pl/obszary-tematyczne/inne-opracowania/wyznania-religijne/wyznania-religijne-w-polsce-20122014,5,1.html (2018.10.31).

11. Mandle HB, Cahill KE, Fowler KM, et al. Reasons for discontinuation of reversible contraceptive methods by women with epilepsy. Epilepsia. 2017; 58(5): 907-914, doi: 10.1111/epi.13734, indexed in Pubmed: 28369748.

12. EuropeanMedicinesAgency. http://www.ema.europa.eu/docs/en_ GB/document library/Referrals document/Valproate 2017 31/European_Commission_final_decision/WC500250216.pdf (2018.09.15).
13. Tomaszewski J, Paszkowski T, Debski R, et al. [The CHOICE study (Contraceptive Health Research Of Informed Choice Experience) - an educational research program for Polish women planning combined hormonal contraceptives use]. Ginekol Pol. 2012; 83(6): 417-423, indexed in Pubmed: 22880460.

14. Jędrzejczak J, Bomba-Opoń D, Jakiel G, et al. Managing epilepsy in women of childbearing age - Polish Society of Epileptology and Polish Gynecological Society Guidelines. Ginekol Pol. 2017; 88(5): 278-284, doi: 10.5603/GP.a2017.0053, indexed in Pubmed: 28580576.

15. Reddy DS. Clinical pharmacokinetic interactions between antiepileptic drugs and hormonal contraceptives. Expert Rev Clin Pharmacol. 2010; 3(2): 183-192, doi: 10.1586/ecp.10.3, indexed in Pubmed: 20369030.

16. Reimers A. Contraception for women with epilepsy: counseling choices, and concerns. Open Access J Contracept. 2016; 7: 69-76, doi: 10.2147/OAJC.S85541, indexed in Pubmed: 29386938.

17. Herzog AG, Mandle HB, Cahill KE, et al. Differential impact of contraceptive methods on seizures varies by antiepileptic drug category: Findings of the Epilepsy Birth Control Registry. Epilepsy Behav. 2016; 60: 112-117, doi: 10.1016/j.yebeh.2016.04.020, indexed in Pubmed: 27206228.

18. Vieira CS, Pack A, Roberts $K$, et al. A pilot study of levonorgestrel concentrations and bleeding patterns in women with epilepsy using a levonorgestrel IUD and treated with antiepileptic drugs. Contraception. 2018 [Epub ahead of print], doi: 10.1016/j.contraception.2018.11.018, indexed in Pubmed: 30529085. 